\title{
Coin of the Realm: Practical Procedures for Determining Authorship
}

\author{
Thomas F. Babor, Dominique Morisano and \\ Jonathan Noel
}

Like a coin, authorship has two sides: credit and responsibility. One receives professional credit from his/her publications and takes responsibility for their contents.

Biagioli et al. (1999, p. 2)

\section{Introduction}

Authorship credit is conceivably the most important and least understood area of professional life for members of the scientific community. Because promotion, prestige, and productivity are judged largely by publication activity, authorship credit has become the "coin of the realm" in the scientific marketplace (Wilcox, 1998). The two sides of this coin are credit and accountability. The assignment of individual credit to a publication implies certain ethical and scientific imperatives that are of tremendous importance to the scientific enterprise (Rennie \& Flanagin, 1994). These imperatives include the certification of public responsibility for the truth of a publication and the equitable assignment of credit to those who have contributed in a substantive way to its contents.

The need for clear and consistent procedures for the determination of authorship credits comes from two considerations. First, many journals are now demanding that articles be prepared in a way that is consistent with the

\section{How to cite this book chapter:}

Babor, T F, Morisano, D and Noel, J. 2017. Coin of the Realm: Practical Procedures for Determining Authorship. In: Babor, T F, Stenius, K, Pates, R, Miovský, M, O'Reilly, J and Candon, P. (eds.) Publishing Addiction Science: A Guide for the Perplexed, Pp. 207-227. London: Ubiquity Press. DOI: https://doi.org/10.5334/bbd.k. License: CC-BY 4.0. 
principles of responsible authorship. Second, a clear consensus about the conditions governing authorship decisions would make the work of individual authors much easier.

Numerous professional organizations (e.g., American Psychological Association, 2010), expert panels (International Committee of Medical Journal Editors, 1991, 2003, 2013), and individual commentators (Rennie et al., 1997) have developed policies and procedures dealing with individual, group, and corporate authorship. In this chapter, we review some of these guidelines from both the practical and ethical perspectives, in an attempt to develop workable procedures that authors can follow during the course of preparing and publishing a scientific article. In addition, we consider authorship problems that sometimes arise in the course of a publication cycle.

Authorship problems seem to be occurring with increasing frequency (Wilcox, 1998). Of 785 authors abstracted from 121 articles published in The Lancet, $44 \%$ did not meet the most lenient guidelines for authorship and $60 \%$ of the most common contributor's activities overlapped with those on acknowledgement lists (Yank \& Rennie, 1999). Among Cochrane Reviews, 39\% of publications had evidence of honorary authors, and $9 \%$ had evidence of ghost authors (Mowatt et al., 2002). An analysis of ghost and honorary authorship among articles published within six leading medical journals (e.g., JAMA, The Lancet) in 2008 found that, although there appeared to have been a decrease in ghost authorship, specifically over the previous decade, the prevalence of articles with honorary and/or ghost authorship was still 21\% (Wislar et al., 2011). Within 10 top peer-reviewed nursing journals, an even greater number (42\%) of articles published in a twoyear period contained honorary authors, and $27.6 \%$ had ghost authors (Kennedy et al., 2014). Undeserved authorships; failure to credit collaborating authors; relaxed policies for students, research assistants, and postdoctoral fellows; and an excessive number of co-authors are all serious problems. Some journals have gone so far as to limit the number of authors who can be listed on a submission (e.g., The American Journal of Public Health lists the cap as six).

The pervasiveness of ethical issues in authorship is suggested by the extent to which scientific readers can be amused by the satirical humor epitomized in the "Ode to multi-authorship" quoted in Box 11.1.

All cases complete, the study was over the data were entered, lost once, and recovered.

Results were greeted with considerable glee $\mathrm{p}$ value (two-tailed) equalling 0.0493.

The severity of illness, oh what a discovery, was inversely proportional to the chance of recovery.

When the paper's first draft had only begun 
the wannabe authors lined up one by one.

To jockey for their eternal positions

(for who would be first, second, and third)

and whom "et aled" in all further citations.

Each centre had seniors, each senior ten bees,

the bees had technicians and nurses to please.

The list it grew longer and longer each day, as new authors appeared to enter the fray.

Each fought with such fury to stake his or her place being just a "participant" would be a disgrace.

For the appendix is piled with hundreds of others and seen by no one but spouses and mothers. If to "publish or perish" is how academics are bred then to miss the masthead is near to be dead. As the number of authors continued to grow they outnumbered the patients by two to one or so. While PIs faxed memos to company headquarters the bees and the nurses took care of the orders. They'd signed up the patients, and followed them weekly heard their complaints, and kept casebooks so neatly. There were seniors from centres that enrolled two or three who threatened "foul play" if not on the marquee.

But the juniors and helpers who worked into the night were simply "acknowledged" or left off outright. "Calm down" cried the seniors to the quivering drones there's place for you all on the RPU clones. When the paper was finished and sent for review six authors didn't know that the study was through. Oh the work was so hard, and the fights oh so bitter for the glory of publishing and grabbing the glitter. Imagine the wars when in six months or better The Editor's response, "please make it a letter".

RPU=repeating publishable unit; $\mathrm{PI}=$ principal investigator

Reprinted from The Lancet, 348, HW Horowitz, NH Fiebach, SM Levitz, J Seibel, EH Smail, EE Telzak, GP Wormser, RB Nadelman, M Montecalvo, J Nowakowski, and J Raffall, "Ode to multiauthorship: A multicentre, prospective random poem, 1746, 1996, with permission from Elsevier.

Box 11.1: Ode to multiauthorship: A multicentre, prospective random poem. 


\section{Conventions in Assigning Order of Authorship}

One of the difficulties in determining the criteria for authorship comes from the different traditions and practices that have been used to distribute authorship credits. Table 11.1 provides definitions of common authorship terms and ethical issues, some of which are also discussed in Chapters 5 and 14.

Authors are sometimes listed in alphabetical order to avoid controversy about the relative contributions of different authors, especially when the contributions have been fairly equal. A related convention is to list authors in reverse alphabetical order, presumably to avoid the preference given to persons whose surname begins with a letter that appears early in the alphabet. Another convention is to list the laboratory director, center director, or other prominent person last. As noted in other parts of this chapter, this convention is not ethical unless that individual has made a substantial contribution to the publication and is not being listed merely to flatter the powerful or to add to the prestige value of the authorship list. This convention can also cause confusion when comparing contributions across fields. For instance, a last author might be presumed by some professionals to have contributed the least to an article and by others to have backed the entire project.

The convention followed most frequently in the addiction field is to list authors according to their relative contributions, with the first author assumed to be responsible for writing the article, corresponding with the journal editor, and making the most substantive contributions. The first author in such a system is sometimes called the corresponding author. In some cases a senior researcher who is not the first author is designated as corresponding author to facilitate the progress of the manuscript through the peer-review process. This practice is not acceptable if the main purpose is to take advantage of this researcher's influence and prestige, rather than to reflect actual contributions to the manuscript.

Although the convention is assumed to be based on the equitable distribution of authorship credits, the relative ordering of authors is often dependent on the first author's subjective judgment of others' contributions. In the absence of conducting an inventory of contributions, effort, and follow through, it is likely that some contributors will receive more credit than they deserve, and others less, solely because of the ambiguity and arbitrariness of the process.

With the growth of multicenter clinical trials and other "big-science" collaborative projects, corporate authorship has also increased. This convention lists a team name as the author, with a footnote or acknowledgement describing the contributors and the corresponding author. One reason for this convention is to make citations and referencing more efficient in cases where there are large numbers of contributors. Corporate authorship might also help to avoid the difficulties associated with determining who contributed what to a 


\begin{tabular}{|c|}
\hline Coercion authorship \\
\hline is a gift authorship that is demanded rather than voluntarily awarded. \\
\hline Contributorship \\
\hline $\begin{array}{l}\text { consists of listing the contributions of each person involved in the project, avoid- } \\
\text { ing the attribution of authorship entirely. }\end{array}$ \\
\hline Corporate authorship \\
\hline $\begin{array}{l}\text { lists the name of a project as author, along with a separate acknowledgement } \\
\text { describing the contributors and the corresponding author (as an alternative to long } \\
\text { author lists in multi-authored reports). }\end{array}$ \\
\hline Corresponding author \\
\hline $\begin{array}{l}\text { is often the first author listed on an article, assumed to be the main researcher and } \\
\text { writer of the article and the person responsible for corresponding with the journal } \\
\text { editor. In some cases the corresponding author is not listed first when the writing } \\
\text { and corresponding functions are divided. }\end{array}$ \\
\hline Ghost authorship \\
\hline $\begin{array}{l}\text { is the failure to include as co-author of a work a person who satisfies the criteria } \\
\text { for authorship (e.g., a science writer employed by a drug company). }\end{array}$ \\
\hline Gift authorship \\
\hline $\begin{array}{l}\text { awards authorship credit because of a person's power or prestige rather than for } \\
\text { substantial contribution to the work. }\end{array}$ \\
\hline Group authorship \\
\hline See "Corporate authorship." \\
\hline Guarantor \\
\hline $\begin{array}{l}\text { is the person who takes responsibility for the contents and integrity of the work as } \\
\text { a whole. }\end{array}$ \\
\hline Honorary authorship \\
\hline See "gift authorship." \\
\hline Mutual-admiration authorship \\
\hline $\begin{array}{l}\text { occurs when two or more researchers agree to list each others' names on their } \\
\text { own articles despite the others' minimal involvement. }\end{array}$ \\
\hline Mutual-support authorship \\
\hline See "mutual-admiration authorship." \\
\hline Pressured authorship \\
\hline See "Coercion authorship." \\
\hline Surprise authorship \\
\hline $\begin{array}{l}\text { occurs when a researcher finds out after publication that his or her name appears } \\
\text { on an article. }\end{array}$ \\
\hline
\end{tabular}

Table 11.1: Forms of authorship. 
multi-authored article, and how much credit each author should receive. Some journals require contributors to formally name at least one person in the masthead, however (e.g., Alexander Bloggins for the Addiction Research Group).

When participating in multidisciplinary or international collaborations, differing authorship conventions must also be taken into account, as authorship criteria and authorship order can have significantly different connotations in different disciplines (Anderson et al., 2011). As noted previously, in some disciplines, the last author may indicate the person who contributed the least effort, whereas in others it might signify the senior author or laboratory head.

Because of the problems associated with determining who merits authorship credit, one editor (Smith, 1997) proposed the concept of contributorship. This involves listing the contributions of each person involved in the project, and avoiding the attribution of authorship entirely. Although this convention has not been adopted by any journal in its pure form (probably because the problems it causes with referencing), some journals, such as the American Journal of Public Health, request that all authors list their contributions when an article is submitted and publish a summary as a footnote or acknowledgement (American Journal of Public Health Instructions for Authors at ajph.aphapublications. org/page/authors.html).

In summary, a variety of conventions have been used to arrange the names of individual contributors in multi-authored articles. Some conventions are used more than others, with the main-author-first convention used most often. Other conventions (e.g., group authorship) tend to be used in special situations as the case demands. The purpose of these conventions, particularly more recent variants, is to assure that proper credit is assigned so that individual responsibility for a publication can be inferred by the reader.

\section{Publication Policies and Publication Misconduct}

Over the past 25 years, journal editors, research administrators, and funding agencies have devoted increasing attention to the ethical and practical issues of scientific authorship. Concern about authorship has been heightened by a number of events and situations that have at times compromised, and at other times embarrassed, the entire scientific enterprise (Box 11.2 and Box 11.3).

The most flagrant examples involve scientific misconduct. In a number of well-publicized cases (Broad \& Wade, 1982), investigators have published scientific articles that have been retracted because the data were fraudulent or the contents plagiarized from other sources. What is remarkable about many of these cases is that, in addition to the person directly involved in scientific misconduct (e.g., John Darsee, who was the lead author on numerous fraudulent articles; Relman, 1983), there have typically been a number of co-authors who apparently had no idea that the senior author was fabricating data or copying others' ideas. This implies that in some cases co-authors are not in a position 
In 1983 and 1986, the International Advertising Association published pro-tobacco reports on tobacco advertising bans and smoking prevalence, with the work credited to Dr. J. J. Boddewyn of Baruch College, The City University of New York (Davis, 2008). Supporters of the tobacco industry enthusiastically touted the reports, but a later review of publicly available tobacco industry documents paints a different picture. Not only were the reports ghost written by Paul Bingham, then an employee of British American Tobacco, but Dr. Boddewyn was also a paid consultant of the tobacco industry, and the research itself was highly flawed. The relationship between Mr. Bingham, British American Tobacco, Dr. Boddewyn, and the International Advertising Association was not disclosed in the reports or in later hearings in front of the U.S. Congress.

Box 11.2: Ghost authorship by the tobacco industry.

In the journal Science, Dr. Gerald P. Schatten was listed as a cocorresponding author and senior author of an article on a highefficiency method for generating stem cells (University of Pittsburg, 2006). Soon after publication, allegations of scientific misconduct, including scientific fraud and data manipulation, on the part of Dr. Woo Suk Hwang, the lead author, were made public and ultimately the article was retracted. Although Dr. Schatten was absolved from participating in any misconduct, he was culpable for research misbehavior. Dr. Schatten wrote much of the article but did not verify the authenticity of the raw data and did not critically examine discrepancies that occurred through the drafting process. An investigative board ruled that Dr. Schatten assumed senior authorship to enhance his scientific reputation, improve opportunities for funding, and obtain financial benefit. The board also ruled that only a few of the 25 authors listed had actually read the article before submission.

Box 11.3: Gift authorship of a retracted article.

to take public responsibility for the contents of a scientific report, which is now considered to be one of the main criteria for authorship credit. In reality, there is a significant amount of basic trust across a number of domains that authors must invest in each other when collaborating on a publication, no matter what 
their authorship position. Basic domains include honesty regarding the originality of the origins of any writing contributions, open disclosure about any conflicts of interest (e.g., financial investment in a business that is dependent on research outcomes, personal relationships with potential reviewers), and being thorough and ethical in any data entry and statistical analyses. With the rise in publication pressures that authors face at their own institutions and funding agencies (e.g., having to produce a minimum number of publications per year to stay employed), it is important to address a range of ethical concerns in publishing. In its updated statement on authorship standards for submissions to biomedical journals, the International Committee of Medical Journal Editors (2013) indicates that authors should be able to identify the specific parts of an article that the other co-authors have been responsible for.

Extreme cases aside, the abuse of scientific authorship has been suspected in an even greater number of cases where the scientific misconduct is much more subtle. Examples include the addition of authors to curry favor, conferring coauthorship by virtue of status or power, rewarding students or junior faculty with co-authorship to advance their careers, and adding a prominent name to a list of co-authors to receive a more sympathetic editorial review. Related to these problems and to the ever-growing importance of "research productivity" are disturbing trends toward the proliferation of authorship credits attached to publications, a growth in the number of mediocre quality publications ("paper inflation"), and the multiplication of reports using the "least publishable unit" to maximize the output from a single study (Lafollette, 1992).

In part to prevent these kinds of problems, many journal editors and other individuals in scientific publishing have promoted policies designed both to detect misconduct and prevent the more blatant forms of authorship abuse. These policies include publishing detailed descriptions of the criteria for scientific authorship, requiring that all authors sign a statement of authorship responsibility, putting limits on the number of authors listed on the masthead, and requesting that co-authors provide a written explanation of their individual contributions to a publication.

How does all of this apply to individual authors? Even if most authors in the addiction field have never encountered an instance of data fabrication or plagiarism, they are likely to encounter the more subtle forms of irresponsible authorship and publication misconduct, such as gift authorship and ghost authorship (Flanagin et al., 1998). Honorary or gift authorship consists of awarding authorship credit because of the person's power and prestige or as "payment" for another kind of contribution rather than for time, effort, and substantive contributions to the work. An extreme example of this is surprise authorship, where a researcher finds out that his or her name appears on an article only after publication (Anderson et al., 2011). When someone demands (and receives) an honorary authorship, it is sometimes called a coercion authorship or pressured authorship (Claxton, 2005; Freeser, 2008). Closely related to gift authorship is mutual-admiration or mutual-support authorship, 
in which two or more researchers agree to list each other as authors despite little involvement in each other's articles, usually as a means to expand their individual publication histories (Claxton, 2005). Ghost authorship refers to the failure to include as co-authors those who satisfy the criteria for authorship (Sheikh, 2000). This happens most often in the publication of pharmaceutical company trials in which an industry-paid scientific writer drafts the article but is not listed as a co-author to avoid the perception of conflict of interest. It also occurs with funded students and research assistants (Newman \& Jones, 2006) who might contribute substantively to a publication but do not receive credit because the contribution is considered "part of the job."

In the remainder of this chapter, we review guidelines that have been developed to deal with publication misconduct and then some practical steps that can be taken by individuals, project teams, centers, departments, and professional organizations to ensure responsible authorship.

\section{Formal Guidelines}

To develop a more coherent, equitable, and ethical set of guidelines for addiction journals, various policies have been proposed in the scientific literature. These policies include the guidelines recommended by the Council of Science Editors (Biagioli et al., 1999), the Sigma Xi standards for responsible authorship (Jackson \& Prados, 1983), the statement of the International Committee of Medical Journal Editors (2013), and a variety of proposals from individual commentators (e.g., Broad \& Wade, 1982; Fine \& Kurdek, 1993; Newman \& Jones, 2006). Box 11.4 describes the general guidelines developed by the American Psychological Association (2010). These have been the subject of a considerable amount of interpretation and discussion in the psychological literature, and some attempts have been made to develop operational definitions of the specific criteria.

Winston (1985) developed a system in which points are assigned for various professional contributions to a scholarly publication, with research design and report writing earning the most points. A certain number of points must be earned to qualify for authorship credit, and the individual with the highest number is granted first authorship.

One of the most cited sources on authorship is the 1985 consensus statement of the International Committee of Medical Journal Editors (1985). The statement indicated that only those in a position to take public responsibility for the work could claim authorship. Although this definition would preclude gift authorship and help to minimize ghost authorship, there were still problems with the definition of a "substantial" contribution (see Yank \& Rennie, 1999) especially in situations in which collaborating investigators band together on a project to take advantage of expertise that is unlikely to be concentrated in one individual. These problems were corrected in a 2003 revision to this statement 
Psychologists take responsibility and credit, including authorship credit, only for work they have actually performed or to which they have substantially contributed. Principal authorship and other publication credits accurately reflect the relative scientific or professional contributions of the individuals involved, regardless of their relative status. Mere possession of an institutional position, such as department chair, does not justify authorship credit. Minor contributions to the research or to the writing for publications are acknowledged appropriately, such as in footnotes or in an introductory statement. Except under exceptional circumstances, a student is listed as principal author on any multiauthored article that is substantially based on the student's doctoral dissertation. Faculty advisors discuss publication credit with students as early as feasible and throughout the research and publication process as appropriate.

Box 11.4: Authorship guidelines proposed by the american psychological association.

Source: Section 8.12, American Psychological Association (2010).

and further revised in 2013 (see www.icmje.org). The International Committee of Medical Journal Editors now indicates that each author should meet the following criteria: (a) substantial contributions to the conception or design of the work or the acquisition, analysis, or interpretation of the data; (b) drafting the work or revising it critically for important intellectual content; (c) approval of the final version to be published; and (d) agreement to be accountable for all aspects of the work in ensuring the questions related to the accuracy or integrity of any part of the work are appropriately investigated and resolved. In addition, the International Committee of Medical Journal Editors recommends that an author should have confidence in the contributions of their co-authors and be able to identify which parts of the work he or she was responsible for. Additional changes were made by the International Committee of Medical Journal Editors to deal with contributors who do not meet authorship criteria, such as people who provide general supervision or administrative support for a research group, technical help, writing assistance, language editing, or proofreading. These individuals and their contributions should be listed in an acknowledgements section. To the extent that a listing of such persons could be interpreted as an endorsement of the data or conclusions, the International Committee of Medical Journal Editors concluded that all persons listed must provide written permission to be acknowledged. 


\section{Practical Steps to Determine Authorship}

The foregoing discussion of conventions, problems, and policies suggests that authorship of an article is foremost a social process that requires a considerable amount of discussion, negotiation, and influence. If there is a general perception that the procedures for attributing authorship credits are inadequate and ineffective (see Yank \& Rennie, 1999), then it may be because the social nature of authorship has not been taken into account in the design of policies and procedures for responsible authorship. Most guidelines focus on individual accountability in relation to abstract ethical principles, with bureaucratic controls and punitive sanctions emphasized instead of practical guidance about what to do at the level of the group where real influence and control are concentrated. In this section, we describe a model process to demonstrate how many of the helpful suggestions provided in the literature on scientific authorship can be implemented in a practical, systematic, and open way. The process is based on the assumption that, because the writing of a multi-authored article is a social process, the responsibility, accountability, and equitable distribution of credit reside in the group of individuals most responsible for conducting the research and writing the article. This process can easily be implemented by an external agency or even within an institution, department, or research center. It needs to be conducted in an open, democratic, and ethical way so that all collaborating investigators agree to accept the basic values of scientific integrity.

As in any group process, one or more individuals need to take a leadership role. There is general agreement in the scientific community that the person most closely associated with the project should take responsibility for drafting the article and being first author. Exceptions to this rule are possible, such as when the investigator who conceived and directed a project cedes responsibility to a junior investigator who made special contributions and who is capable of carrying the written report to a successful conclusion. A crucial skill that should be taken into account in the choice of one or more leaders for a scientific publication is familiarity with the authorship issues described in this chapter. If the person has had no formal training in research ethics, the articles cited in the reference section of this chapter should be reviewed, giving special attention to several key sources (e.g., Fine \& Kurdek, 1993; International Committee of Medical Journal Editors, 2013).

To avoid conflict, misunderstandings, and publication misconduct, both the lead author and the group should follow generally accepted procedures that are characterized by openness and transparency and should decide as early as possible who will be listed as an author, the order of authorship, and the other contributors to mention in the acknowledgments (American Psychological Association, 2010). In the following paragraphs, we provide an outline for a model that can be modified to fit the needs of a project team.

The model requires the completion of specific tasks at each of three stages in the publication process. As described below, periodic discussions about 
authorship and accountability should be conducted at the planning stage, the drafting stage, and the finalization stage of a publication. According to Lafollette (1992), "The issue is absolutely clear. Who did what and how much? Answering those questions early on-and continuing to ask them as projects change-can help to prevent disputes or embarrassment later" (p. 107).

\section{Planning Stage}

The planning stage of the publication process begins when a scientific investigation or other project (e.g., a review article) has advanced to the point where it is likely that a scientific article is appropriate or warranted. This decision is usually made by the project leader, who either takes direct responsibility for the direction of the publication or designates one or more individuals to initiate the publication planning process. The following tasks and activities are suggested.

- One or more senior members of the research or writing team take responsibility for developing an outline of the article, a timetable for the completion of the article, and a list of potential co-authors, based on actual contributions to date and expected contributions in the future. The outline is distributed to all prospective authors, with the understanding that authorship will depend on substantive contributions, as well as effort and follow through, as described in relevant policies and publications (including this chapter).

- Plans are made for a periodic reassessment of the research team's contributions throughout the planning, drafting, and finalization stages. If it is found that previous expectations are not being met, then assignment of authorship credit may be modified, based on actual contributions at the time of publication completion.

- Relevant policies and publications (including copies of this chapter) are distributed to prospective authors along with the outline.

- A meeting is called to discuss the proposed publication and the distribution of responsibilities for its completion. Assignments are made for data analysis and writing sections of the first draft. A timeline of key tasks is distributed and discussed.

\section{Drafting Stage}

After the first draft of an article is completed or as relevant sections are finished, the drafting author or authors circulate the article for comments. At this stage, potential authors must be reminded not only about their rights to possible authorship but also about their responsibilities.

A crucial task at this stage is to identify who qualifies for formal authorship credit according to generally accepted criteria for responsible authorship. One 
way to accomplish this task is to ask all potential contributing authors (including the lead author) to describe their contributions to the project. Box 11.5 provides a checklist of contributions that prospective authors could be asked to complete by the lead author in order to determine eligibility for authorship at this stage. Although this one was designed for original research reports and may not apply to all publication types (e.g., reviews), similar disclosure checklists have been found to be useful for determining authorship credit (Yank \& Rennie, 1999).

Once the checklists are completed, the lead author could call a meeting to discuss authorship and other matters related to the proposed publication. At the meeting, each person is asked to describe his or her contributions to the project to date. In such a setting, individuals often reveal contributions that others were not aware of and, in other cases, describe activities that might not be considered substantial in comparison with those of others. At this time, it is important to discuss generally accepted criteria for authorship, such as those listed in Box 11.5, to make sure that everyone agrees on the standards for determining who should be listed on the article and in what order the names should be arranged. To provide authority to the process, it could be advantageous to mention that most journals now require a similar process of asking authors to sign a statement attesting that they have met minimal criteria for authorship, and some journals (e.g., The Lancet, BMJ, American Journal of Public Health) require authors to describe their individual contributions, the text of which is published along with the article.

One of the most difficult decisions in the assignment of authorship credit is the distinction between major (or substantial) and minor contributions. A major contribution usually involves the independent development or interpretation of ideas that are crucial to the advancement of a scientific study or a scholarly article. It may also involve the use of special skills to perform a complex task without which the project could not have been done, such as the application of a sophisticated statistical technique. The emphasis in these definitions is more on quality than quantity. All persons making major contributions should receive authorship credit, provided that they also participate in the writing of the article and any revisions required by the editor. Such individuals should also be capable of taking public responsibility for both general and specific aspects of the publication, recognizing that opinions differ as to what this means. Although the checklist provided in Box 11.5 was compiled from a variety of sources, we borrowed heavily from Yank and Rennie (1999), who distinguished between "major" and "partial" contributions. In a content analysis of articles in which authors provided a description of their roles in the publication process, they also report the 10 most common author contributions. A major contribution meant that the contributor fulfilled a majority of the activities for a given category (examples below). A partial or minor contribution referred to a more limited role, presumably in terms of time, effort, or substance. 
Instructions: Use the checklist to describe your contributions to the project to date. Under each item you have checked, describe the nature of your contribution, the amount of effort you put into it (e.g., hours, days, months), and whether your contribution fulfilled all of the requirements for that task or some of the requirements (e.g., in collaboration with others, you wrote part of the article or you collected part of the data).

- Were responsible for conception of the project (planning meetings, drafting of research proposal, etc.)

- Reviewed the literature

- Obtained funding or other resources

- Assembled the project team

- Coordinated study (5) by assigning responsibilities and tasks

- Trained of personnel

- Supervised personnel

- Obtained human (or animal) subjects approvals

- Designed the methodology or experimental design (2)

- Advised on design or analysis (9)

- Wrote the research protocol

- Collected data (4), including follow-up data

- Performed clinical analysis or management (6)

- Performed randomization or matching

- Performed statistical analysis of data (8)

- Interpreted the data (3)

- Performed economic analysis of data

- Managed data (10)

- Provided technical services (coding questionnaires, laboratory analyses (7), etc.)

- Provided or recruited patients

- Provided materials or facilities

- Presented and defended findings in a public forum

- Wrote draft of article

- Wrote final version of article (1)

- Submitted report for publication

- Responded to reviewers' comments

- Were responsible for other activity or service (describe)

Box 11.5: Checklist for conducting an inventory of major and minor contributions to a scientific article.

Note: The numbers in parentheses refer to the top-10 overall categories of contribution identified by Yank and Rennie (1999) in a content analysis of articles according to the most frequently mentioned contributions to authorship. 
Examples of major contributions that fulfilled Yank and Rennie's (1999) "lenient" interpretation of the International Committee of Medical Journal Editors (1991) authorship criteria were (a) conception of the idea for the study or article, (b) design of the study, (c) statistical analysis or interpretation of data, (d) laboratory analysis, (e) management or analysis of clinical aspects, and (f) performance of field work or epidemiology. Anyone who wrote or revised the article (even sections) fulfilled the second part of the criteria (i.e., drafted the article or revised it critically for important intellectual content).

In considering the relative importance of major contributions, we believe two additional factors should be taken into account by the project leader and team: effort and follow through. Effort pertains to the amount of time spent on the particular contribution. Follow through involves active participation at various stages throughout the project. For example, if a person has participated in a study in a minor way or has made a major contribution that involves minimal effort (e.g., the development of an idea for the study or a novel hypothesis) and/ or follow through, this does not necessarily entitle the individual to authorship if other persons have made greater contributions with respect to effort and follow through.

Nonsubstantive considerations should not determine the order of authorship or whether to include an individual as an author. Examples of nonsubstantive factors include rank or status, need for publication credits to justify advancement, involvement in the project as a consequence of routine duties for which the individual is paid (e.g., collecting laboratory samples), or ability to provide access to study participants. The person who is named as the principal investigator of a project or a grant for administrative reasons might not even qualify for authorship under these circumstances if she or he has had no role in the design and conduct of a particular project (e.g., the secondary analysis of data collected for another purpose).

Members of a research team also need to recognize that, in general, individuals will be expected to contribute to projects in a collegial fashion without necessarily receiving credit in all project publications. And, as noted in Chapter 5, the group may want to give consideration to the special situation of students and postdoctoral fellows where different standards for a contribution may apply.

Taking all of the above information into account, it should not be difficult in most cases to reach consensus about who qualifies for authorship and what the most equitable relative ranking of contributions should be. When contributions are discussed in an open forum in relation to generally accepted criteria and ethical principles, secondary (nonsubstantive) considerations tend to be difficult to defend, especially when there is a written record of each individual's perceived contributions. If there are discrepancies between what an individual perceives to be his or her contributions and the perceptions of others, these differences often can be resolved through open discussion. 


\section{Finalization Stage}

Before an article is formally submitted to a journal, a corresponding author needs to be designated. This person is usually the first author, but sometimes it is also the senior project leader in cases in which the first author is inexperienced with publication submission. A prominent or senior co-author should never be designated as corresponding author solely to influence the review process. If there is general agreement about the authorship order throughout the writing process, this order can be reviewed again at the final stage to determine whether preparation and revision altered the relative order of contributions enough to require changes.

\section{Authorship Disputes}

If attempts to resolve authorship status before writing or publishing a manuscript are unsuccessful, four processes for authorship dispute resolution have been proposed: direct dialogue, mediation, peer panel, and a binding decision (National Institutes of Health, 2010). Direct dialogue requires the parties in a dispute to discuss their differences with each other in order to reach an agreeable solution. If direct dialogue is unsuccessful, they may enter mediation, which uses a neutral, third-party mediator to assist in finding a resolution. Parties in dispute may also present their perspectives on authorship to a three-person peer panel and agree to abide by the panel's decision. If the dispute remains unresolved, then a scientific director or person in a similar position may make a binding decision. Although these processes have been created by a U.S. institution, they are applicable to any research environment and can be modified to best suit the authors' circumstances.

\section{Conclusion}

Intellectual honesty is a fundamental ingredient of scientific integrity, and this extends to the need for complete accuracy and transparency in representing contributions to research reports and other scientific writing. The contributions of colleagues and collaborators need to be recognized in all scientific publications, but authorship must be assumed or awarded only on the basis of substantive contributions to an article and the ability of its authors to take public responsibility for its contents or, at least, for major parts of the contents. Decisions regarding authorship should be seen as part of a process that begins with the development of a publication plan and ends with the final revision of an accepted article. In between, it is best to have all potential contributors to a publication participate in an open process of stating their perceived contributions to a given project in the context of generally accepted 
criteria for authorship. Such a process is likely to manage expectations and prevent publication misconduct as well as misunderstandings and conflicts. To the extent that authorship credit continues to be seen as the coin of the realm in addiction science, both sides of the coin (credit and responsibility) need to be valued.

\section{Authorship Credit Exercise}

Appendix A contains two case studies that describe sensitive and possibly contentious authorship credit scenarios. For each case, answer the questions at the end and then discuss your answers with colleagues or a mentor in order to apply the principles described in this chapter. Also review Chapters 5, 14, and 15 for additional information about resolving ethical dilemmas in relation to authorship.

\section{Acknowledgements}

The authors thank Ian Stolerman for his helpful comments and suggestions.

Please visit the website of the International Society of Addiction Journal Editors (ISAJE) at www.isaje.net to access supplementary materials related to this chapter. Materials include additional reading, exercises, examples, PowerPoint presentations, videos, and e-learning lessons.

\section{References and Additional Reading}

American Psychological Association Ethics Committee. (2010). Ethical principles of psychologists and code of conduct including 2010 amendments. Retrieved from http://www.apa.org/ethics/code/principles.pdf.

Anderson, M., Kot, F. C., Shaw, M. A., Lepkowski, C. C., \& De Vries, R. G. (2011). Authorship diplomacy: Cross-national differences complicate allocation of credit and responsibility. American Scientist, 99, 204-207. DOI: https://doi.org/10.1511/2011.90.204

Biagioli, M., Crane, J., Derish, P., Gruber, M., Rennie, D., \& Horton, R. (1999). CSE Task force on authorship draft white paper. Retrieved from http://www. councilscienceeditors.org/resource-library/editorial-policies/cse-policies/ retreat-and-task-force-papers/authorship-task-force/cse-task-force-onauthorship/.

Broad, W., \& Wade, N. (1982). Betrayers of the truth: Fraud and deceit in the halls of science. New York, NY: Simon \& Schuster. 
Claxton, L. D. (2005). Scientific authorship. Part 2: History, recurring issues, practices, and guidelines. Mutation Research, 589, 31-45. DOI: https://doi. org/10.1016/j.mrrev.2004.07.003

Davis, R. M. (2008). British American Tobacco ghost-wrote reports on tobacco advertising bans by the International Advertising Association and J J Boddewyn. Tobacco Control, 17, 211-214. DOI: https://doi.org/10.1136/ tc. 2008.025148

Feeser, V. R., \& Simon, J. R. (2008). The ethical assignment of authorship in scientific publications: Issues and guidelines. Academic Emergency Medicine, 15, 963-969. DOI: https://doi.org/10.1111/j.1553-2712.2008.00239.x

Fine, M. A., \& Kurdek, L. A. (1993). Reflections on determining authorship credit and authorship order on faculty-student collaborations. American Psychologist, 48, 1141-1147. DOI: https://doi.org/10.1037/0003-066X.48.11.1141

Flanagin, A., Carey, L. A., Fontanarosa, P. B., Phillips, S. G., Pace, B. P., Lundberg, G. D., \& Rennie, D. (1998). Prevalence of articles with honorary authors and ghost authors in peer-reviewed medical journals. JAMA, 280, 222-224. DOI: https://doi.org/10.1001/jama.280.3.222

Horowitz, H. W., Fiebach, N.H., Levitz, S. M., Seibel, J., Smail, E. H., Telzak, E. E., . . Raffalli, J. (1996). Ode to multiauthorship: A multicentre, prospective random poem [Letter to the Editor]. The Lancet, 348, 1746. DOI: https:// doi.org/10.1016/S0140-6736(05)65883-7

International Committee of Medical Journal Editors. (1985). Guidelines on authorship. British Medical Journal, 291, 722. DOI: https://doi.org/10.1136/ bmj.291.6497.722

International Committee of Medical Journal Editors. (1991). Uniform requirements for manuscripts submitted to biomedical journals. New England Journal of Medicine, 324, 424-428. DOI: https://doi.org/10.1056/ NEJM199102073240624

International Committee of Medical Journal Editors. (2003). Uniform requirements for manuscripts submitted to biomedical journals: Writing and editing for biomedical publication. Retrieved from http://www.icmje.org/abouticmje/faqs/icmje-recommendations/.

International Committee of Medical Journal Editors. (2013). Recommendations for the conduct, reporting, editing, and publication of scholarly work in medical journals. Retrieved from http://www.icmje.org/icmje-recommendations. pdf.

Jackson, C. I., \& Prados, J. W. (1983). Honor in science. American Scientist, 71, 462-464.

Kennedy, M. S., Barnsteiner, J., \& Daly, J. (2014). Honorary and ghost authorship in nursing publications. Journal of Nursing Scholarship, 46, 416-422. DOI: https://doi.org/10.1111/jnu.12093

LaFollette, M. C. (1992). Stealing into print: Fraud, plagiarism, and misconduct in scientific publishing. Berkeley, CA: University of California Press. 
Mowatt, G., Shirran, L., Grimshaw, J. M., Rennie, D., Flanagin, A., Yank, V., . . ., Bero, L. A. (2002). Prevalence of honorary and ghost authorship in Cochrane reviews. JAMA, 287, 2769-2771. DOI: https://doi.org/10.1001/ jama.287.21.2769

National Institutes of Health. (2010). Processes for authorship dispute resolution. Retrieved from https://oir.nih.gov/sourcebook/ethical-conduct/ responsible-conduct-research-training/processes-authorship-disputeresolution.

Newman, A., \& Jones, R. (2006). Authorship of research papers: Ethical and professional issues for short-term researchers. Journal of Medical Ethics, 32, 420-423. DOI: https://doi.org/10.1136/jme.2005.012757

Relman, A. S. (1983). Lessons from the Darsee affair. [Editorial]. New England Journal of Medicine, 308, 1415-1417. DOI: https://doi.org/10.1056/ NEJM198306093082311

Rennie, D., \& Flanagin, A. (1994). The Second International Congress on Peer Review in Biomedical Publication. JAMA, 272, 91. DOI: https://doi. org/10.1001/jama.261.5.749

Rennie, D., Yank, V., \& Emanuel, L. (1997). When authorship fails: A proposal to make contributors accountable. JAMA, 278, 579-585. DOI: https:/doi. org/10.1001/jama.1997.03550070071041

Sheikh, A. (2000). Publication ethics and the research assessment exercise: Reflections on the troubled question of authorship. Journal of Medical Ethics, 26, 422-426. DOI: https://doi.org/10.1136/jme.26.6.422

Smith, R. (1997). Authorship: Time for a paradigm shift? [Editorial]. BMJ, 314, 992. DOI: https://doi.org/10.1136/bmj.314.7086.992

University of Pittsburgh. (2006). University of Pittsburgh summary investigative report on allegations of possible scientific misconduct on the part of Gerald P. Schatten, Ph.D. Retrieved from https://ecommons.cornell.edu/ bitstream/handle/1813/11589/Gerald_Schatten_Final_Report_2.08. pdf? sequence $=1$ \&isAllowed $=y$.

Wilcox, L. J. (1998). Authorship: The coin of the realm, the source of complaints. JAMA, 280, 216-217. DOI: https://doi.org/10.1001/ jama.280.3.216

Winston, R. B. (1985). A suggested procedure for determining order of authorship in research publications. Journal of Counseling \& Development, 63, 515-518. DOI: https://doi.org/10.1002/j.1556-6676.1985.tb02749.x

Wislar, J. S., Flanagin, A., Fontanarosa, P. B., \& Deangelis, C. D. (2011). Honorary and ghost authorship in high impact biomedical journals: a cross sectional survey. BMJ, 343, d6128. DOI: https://doi.org/10.1136/bmj.d6128

Yank, V., \& Rennie, D. (1999). Disclosure of researcher contributions: A study of original research articles in The Lancet. Annals of Internal Medicine, 130, 661-670. DOI: https://doi.org/10.7326/0003-4819-130-8-19990420000013 


\section{Appendix A: Authorship Credit Scenarios}

\section{Multicentered Trial with Multiple Investigators}

Dr. Joe Camel is an assistant professor at Small State University where he is the principal investigator of a large, multicenter trial to determine the effectiveness of a new nicotine inhaler at reducing cigarette use and nicotine cravings. The main findings of the study were positive and have already been published in the Journal of Reputable Results. To maximize use of the data collected, Dr. Camel has made the raw data available to each of his colleagues for secondary analyses. It was agreed on by the group that a brief outline of the analyses to be performed and a list of potential co-authors should be prepared by those requesting to use the data to ensure there are no duplicate analyses. The group also agreed to prepare comments and critiques in response to data requests.

Dr. Muck E. Muck, a professor at Ivy League University, informs the Small State group that his team would like to perform an analysis on the effect of alcohol use in nicotine-cessation therapy. In response, Dr. Camel insists on being listed as the last and corresponding author even though he will not contribute to the data analysis, interpretation of the results, or manuscript preparation. Dr. Camel tells Dr. Muck that, as principal investigator of the trial, he has the right to be listed as an author on all related publications, and because he made the data freely available to Dr. Muck, he will not supply the data unless he does so.

\section{Discussion Questions}

1. What are the ethical implications and whose interests are involved?

2. What should Dr. Muck do about the manuscript and the request to add Dr. Camel as a co-author?

3. What should have been discussed among the collaborators before the raw data was made available?

\section{Junior Investigators Sharing Authorship on Each Other's Articles}

Dr. Allen Quidproquo and Dr. Miriam Scratchmyback are the only postdoctoral fellows at the National Center for Addiction Science. They have both been working to publish their dissertation results. Dr. Quidproquo's research focuses on the association of genes with initiation of substance use, whereas Dr. Scratchmyback researches the role of visual cues in treatment and relapse. The two fellows agree that their research has little in common and rarely discuss research topics in the office. But, being the only postdoctoral fellows at their center, they often share 
meals together, talk about their nonacademic lives, and have quickly become friends.

During one meal, Dr. Quidproquo talks about the pressure he is under to publish as often as possible. He can only stretch his data so far and has only a handful of publications to his credit. Dr. Scratchmyback has already been included as an author on more than a dozen publications. Therefore, Dr. Quidproroquo asks Dr. Scratchmyback if he could be a co-author on her publications to bump up his publication numbers, and, in return, he will list Dr. Scratchmyback as a co-author on all of his publications. Dr. Quidproquo reasons that this arrangement would effectively double the amount of publications on his list and substantially add to Dr. Scratchmyback's list as well. He reasons this would better position them for future funding opportunities, faculty positions, and other research awards.

\section{Discussion Questions}

1. How should Dr. Scratchmyback respond to her friend's request?

2. What can Dr. Scratchmyback do to maintain her own scientific integrity and/or prevent his colleague from committing scientific misconduct?

3. To what extent does either fellow stand to gain or lose from this arrangement? 
